\title{
Genetic and immunological characteristics of Type I diabetes mellitus in an Indo-Aryan population
}

\author{
M. A. Kelly ${ }^{1}$, N.S. Alvi ${ }^{2}$, N.J.Croft ${ }^{1}$, C.H.Mijovic ${ }^{1}$, G. F. Bottazzo ${ }^{3}$, A.H. Barnett ${ }^{1}$ \\ ${ }^{1}$ Department of Medicine, Division of Medical Sciences, University of Birmingham, UK \\ ${ }^{2}$ Birmingham Children's Hospital, Birmingham, UK \\ ${ }^{3}$ Scientific Directorate, Bambino Gesú Paediatric Hospital, Scientific Institute, Rome, Italy
}

\section{Abstract}

Aims/hypothesis. Our aim was to characterise the genetic and immunological features associated with Type I (insulin-dependent) diabetes mellitus in a cohort of Indo-Aryan children resident in the United Kingdom.

Methods. Children with Type I diabetes $(n=53)$, unaffected first-degree relatives $(n=146)$ and unrelated healthy control children $(n=54)$ were typed for alleles of the $H L A-D R B 1, H L A-D Q A 1$ and $H L A$ $D Q B 1$ genes. Islet cell antibodies and antibodies to glutamic acid decarboxylase, protein tyrosine phosphatase-2 (IA-2ic) and insulin were measured in the diabetic and control children.

Results. The DRB1*03.DQA1*05.DQB1*02 haplotype was positively associated with the disease, occurring in $78 \%$ of diabetic children compared with $22.6 \%$ of healthy children $\left(p_{c}<2.4 \times 10^{-5}\right)$. In simplex families, this haplotype was transmitted more frequently to the diabetic children than to their unaffected siblings $\left(p<1 \times 10^{-4}\right)$. The DRB1*04.DQA1* 03 .DQB $1 * 0302$ haplotype was also transmitted preferentially to the diabetic probands $(p<0.025)$ but was not associated with disease in the case control study. Islet-related autoantibodies were detected in $89.6 \%$ of diabetic patients compared with $11.8 \%$ of control children $\left(p<1 \times 10^{-6}\right)$. Although protein tyrosine phosphatase- 2 autoantibodies were detected more frequently among DRB1*04-positive diabetic patients compared with patients lacking this allele, the overall frequency of these autoantibodies was lower than observed in Europid diabetic subjects. This could reflect the absence of a disease association with DRB1*04 in the Indo-Aryan cohort.

Conclusion/interpretation. Type I diabetes in our Indo-Aryan cohort is similar to the disease observed in Anglo-Europeans but has important immunogenetic differences. The low frequency of protein tyrosine phosphatase- 2 autoantibodies among the Indo-Aryan diabetic children could have important implications for the design of future strategies for disease prediction in this population. [Diabetologia (2000) 43: 450-456]

Keywords Type I diabetes, Indo-Aryan, immunogenetics, $H L A$ genes, islet-related autoantibodies.
Received: 2 September 1999 and in revised form: 8 November 1999

Corresponding author: Dr. M. A. Kelly, Department of Medicine, Clinical Research Block, Queen Elizabeth Hospital, Edgbaston, Birmingham, B15 2TH, UK

Abbreviations: ICA, Islet cell antibodies; IA-2ic, intracellular fragment of protein tyrosine phosphatase-2; cDNA, complementary DNA; JDF, Juvenile Diabetes Foundation; RR, relative risk; TDT, transmission disequilibrium test.
Type I (insulin-dependent) diabetes results from the progressive autoimmune destruction of pancreatic beta cells [1]. The autoimmune aetiology is signified in Europid populations by a strong association with alleles of the $H L A$ class II histocompatibility genes, particularly those carried on the DR3.DQ2 and $D R 4 . D Q 8$ haplotypes [2], and the presence of circulating antibodies specific for islet antigens including glutamic acid decarboxylase (GAD), the intracellular fragment of protein tyrosine phosphatase-2 (IA-2ic) and insulin $[3,4]$. 
Autoimmune Type I diabetes in childhood is rare in the Asian population of India [5, 6] and is also uncommon among migrant Asian Indian populations in the United Kingdom [7, 8]. The Indian community resident in Birmingham in the United Kingdom is mainly of Indo-Aryan stock and originates predominantly from the Punjab (a region spanning northeast Pakistan to north-west India). The genetic and immunological features associated with Type I diabetes in Indo-Aryans are poorly defined. Previous genetic studies of this population have shown a strong disease association with the HLA-DR3 antigen and a weaker, but inconsistent, association with HLADR4 [9-11]. The disease risk conferred by the $H L A$ $D Q$ alleles has not yet been investigated in this population. Islet cell antibodies (ICA) have been reported to be less frequent among Indo-Aryan diabetic patients than among those of Europid origin [6, 10-13] but the frequency of autoantibodies to GAD, IA-2ic and insulin in the Indo-Aryan population is yet to be determined. The purpose of our study, therefore, was to further analyse the genetic and immunological markers associated with Type I diabetes in a cohort of Indo-Aryan children resident in Birmingham in the United Kingdom. The aim was to establish whether the disease in this group has similar immunogenetic characteristics to those observed in the indigenous Anglo-European population.

\section{Subjects and methods}

Subjects. Children with Type I diabetes $(n=53)$ were recruited from four paediatric diabetes clinics in Birmingham. The patients were unrelated and of Indo-Aryan ethnic origin (both parents originated from Pakistan or the Indian Punjab). All the patients developed diabetes before the age of 16 years and were dependent on insulin from the time of diagnosis. Approximately $50 \%$ of the patients presented with diabetic ketoacidosis and the remaining subjects had hyperglycaemia combined with ketonuria. The cohort consisted of 37 girls and 16 boys and constitutes $93 \%$ of the paediatric Indo-Aryan Type I diabetic population of Birmingham. The mean age of disease onset was $7.1 \pm 4.6$ years (range 2 months to 15 years) and the mean disease duration at the time of recruitment was $3.4 \pm 3$ years (range 1 month to 12 years). Unaffected first-degree relatives $(n=146$, parents or siblings or both of 45 index cases) and 54 healthy control children were also investigated. The control subjects were matched with the diabetic cohort for age at recruitment, sex ratio, ethnic origin and area of residence. The study was approved by the local ethics committee and written informed consent was obtained from all participants.

HLA typing. Genomic DNA was isolated from peripheral blood samples using a Nucleon kit (Scotlab, Strathclyde, Scotland). Alleles of the $H L A-D R B 1, H L A-D Q A 1$ and $H L A$ $D Q B 1$ genes were determined for each of the study subjects using the polymerase chain reaction (PCR) with 48 sequencespecific primer pairs [14]. The PCR products were separated by agarose gel electrophoresis and could be seen under ultraviolet light. The HLA type of each subject was determined from the pattern of allele-specific amplicons.

\section{Detection of islet-related autoantibodies}

Serum samples, taken from the diabetic and control children at the time of recruitment, were analysed for the presence of islet-related autoantibodies.

Cytoplasmic islet cell antibodies (ICA). These were detected by indirect immunofluorescence on unfixed cryostat sections of blood group $\mathrm{O}$ human pancreas, as described previously [15]. Quantification was achieved by assaying serial dilutions of each test serum in parallel with a standard serum, calibrated against an international reference sample of 80 Juvenile Diabetes Foundation (JDF) units. A titre greater than 5 JDF units was considered to be positive. The sensitivity of the assay was $78 \%$ and the specificity was $98 \%$.

Glutamic acid decarboxylase (GAD65) antibodies. These were assayed by immunoprecipitation of radiolabelled human recombinant GAD65, as described previously [16]. Human islet GAD65 complementary DNA (cDNA) was transcribed and translated in vitro in the presence of $\left[{ }^{35} \mathrm{~S}\right]$-methionine. The radiolabelled tracer was incubated overnight with the test serum samples and immune complexes were precipitated with protein A Sepharose (Pharmacia Biotech, Uppsala, Sweden) and quantified by scintillation counting. Antibody titres were expressed as units based on the percentage of radioactivity precipitated by the test serum compared with that precipitated by a reference serum. A titre greater than $13 \mathrm{U}$ was considered positive. The sensitivity of the assay was $77 \%$ and the specificity was $98 \%$.

IA-2ic antibodies. These were detected by immunoprecipitation of in vitro labelled human recombinant IA-2ic, as described for GAD antibodies above. Serum samples were regarded as positive if the antibody titre exceeded $13 \mathrm{U}$. The sensitivity of the assay was $73 \%$ and the specificity was $94 \%$.

Insulin antibodies. These were measured using a micro-radiobinding assay (sensitivity $69 \%$, specificity $98 \%$ ), as described previously [17]. Test serum samples were incubated with ${ }^{125} \mathrm{I}$ labelled human insulin, with and without an excess of unlabelled insulin to correct for non-specific binding. Immune complexes were precipitated with protein A Sepharose and protein G Sepharose (Pharmacia Biotech) and counted for radioactivity. The results were converted into arbitrary units by the use of a standard curve. A titre greater than $4 \mathrm{U}$ was considered positive.

The laboratories in London and Milan, which conducted the antibody assays, have consistently performed well in various proficiency standardisation programmes for ICA determination and, that in Milan, in the combined islet-related autoantibody workshop [18].

Statistical analysis. The association between Type I diabetes and the HLA loci was tested using the chi-squared test or Fisher's exact probability test where appropriate. Corrected $p$ values $\left(p_{c}\right)$ were obtained by multiplying each $p$ value by the number of haplotypes/genotypes analysed. Relative risk (RR) values were calculated for markers which differed significantly in frequency between the diabetic and control groups $\left(p_{\mathrm{c}}<0.05\right)$ using the method of Wolf, with Haldane's modification for 
Table 1. Distribution of $D R / D Q$ haplotypes among diabetic and control subjects

\begin{tabular}{lcc}
\hline $\begin{array}{l}\text { DRB1.DQA1.DQB1 } \\
\text { haplotype }\end{array}$ & $\begin{array}{l}\text { Type I diabetic } \\
\text { patients }(\%) \\
n=50\end{array}$ & $\begin{array}{l}\text { Control } \\
\text { subjects }(\%) \\
n=53\end{array}$ \\
\hline$* 01 . * 0101 . * 05$ & $1(2.0)$ & $4(7.5)$ \\
$* 1501 . * 0102 . * 05$ & $0(0)$ & $5(9.4)^{\mathrm{a}}$ \\
$* 1501 . * 0102 . * 0601$ & $0(0)$ & $6(11.3)^{\mathrm{b}}$ \\
$* 1501 . * 0102 . * 0602$ & $1(2.0)$ & $3(5.7)$ \\
$* 1501 . * 0103 . * 0601$ & $1(2.0)$ & $5(9.4)$ \\
$* 1502 . * 0103 . * 0601$ & $0(0)$ & $7(13.2)^{\mathrm{c}}$ \\
$* 03.005 . * 02$ & $39(78.0)$ & $12(22.6)^{\mathrm{d}}$ \\
$* 04 . * 03 . * 0301$ & $1(2.0)$ & $2(3.8)$ \\
$* 04 . * 03 . * 0302$ & $10(20.0)$ & $7(13.2)$ \\
$* 11 . * 05 . * 0301$ & $3(6.0)$ & $14(26.4)^{\mathrm{e}}$ \\
$* 13 . * 0103 . * 0603$ & $5(10.0)$ & $3(5.7)$ \\
$* 13 . * 0102 * 0604$ & $2(4.0)$ & $2(3.8)$ \\
$* 14 . * 0101 . * 05$ & $6(12.0)$ & $5(9.4)$ \\
$* 07 . * 02 . * 02$ & $3(6.0)$ & $11(20.8)^{\mathrm{f}}$ \\
$* 10 * * 0101 . * 05$ & $5(10.0)$ & $3(5.7)$ \\
\hline
\end{tabular}

Number (\%) of diabetic and control subjects with each haplotype. Only haplotypes observed in more than one subject are shown. ${ }^{\mathrm{a}} p=0.033, p_{\mathrm{c}}=\mathrm{NS} ;{ }^{\mathrm{b}} p=0.016, p_{\mathrm{c}}=\mathrm{NS} ;{ }^{\mathrm{c}} p=0.008$, $p_{\mathrm{c}}=\mathrm{NS} ; \quad{ }^{\mathrm{d}} p<1 \times 10^{-6}, \quad p_{\mathrm{c}}<2.4 \times 10^{-5}, \quad \mathrm{RR}=11.40$ [4.65-27.94]; ${ }^{\mathrm{e}} p<0.01, p_{\mathrm{c}}=\mathrm{NS} ;{ }^{\mathrm{f}} p<0.05, p_{\mathrm{c}}=\mathrm{NS}$

Table 2. Frequency of DRB $1 * 04$ subtypes among DR4.DQ8 positive diabetic and control subjects

\begin{tabular}{lll}
\hline DRB1*04 allele & $\begin{array}{l}\text { DR4.DQ8-positive } \\
\text { diabetic patients }(\%) \\
n=10\end{array}$ & $\begin{array}{l}\text { DR4.DQ8-positive } \\
\text { control subjects }(\%) \\
n=7\end{array}$ \\
\hline$* 0401$ & $2(20.0)$ & $0(0)$ \\
$* 0402$ & $3(30.0)$ & $2(28.6)$ \\
$* 0403$ & $2(20.0)$ & $4(57.1)$ \\
$* 0404$ & $1(10.0)$ & $1(14.3)$ \\
$* 0405$ & $2(20.0)$ & $0(0)$ \\
$* 0407$ & $0(0)$ & $1(14.3)$ \\
\hline
\end{tabular}

Number (\%) of diabetic and control subjects with each allele. $p=\mathrm{NS}$ for all comparisons. Overall $\mathrm{X}^{2}$ for allele distribution in diabetic and control subjects $=5.72(5 \mathrm{df}), p=\mathrm{NS}$

small numbers. Each RR value is quoted with a $95 \%$ confidence interval (95\% CI) [19]. Transmission of HLA susceptibility markers in the Indo-Aryan families was investigated using the transmission disequilibrium test (TDT) [20]. The frequency of islet-related autoantibodies among the diabetic and control subjects was compared using the chi-squared test and Fisher's exact test. These tests were also used to identify associations between autoantibody status and HLA type. The distribution of age-of-onset and disease duration data between groups was analysed using the Kolmogorov-Smirnov test.

\section{Results}

The DRB1*03.DQA1*05.DQB1*02 (DR3.DQ2) haplotype was significantly positively associated with Type I diabetes in the Indo-Aryan cohort $\left(p_{\mathrm{c}}<2.4 \times 10^{-5}, \mathrm{RR}=11.40\right.$ [4.65-27.94]) (Table 1). In contrast, five haplotypes were decreased in fre-
Table 3. Distribution of $D R$ genotypes among diabetic and control subjects

\begin{tabular}{lll}
\hline$D R$ genotype & $\begin{array}{l}\text { Type I diabetic } \\
\text { patients }(\%) \\
n=50\end{array}$ & $\begin{array}{l}\text { Control } \\
\text { subjects }(\%) \\
n=53\end{array}$ \\
\hline$* 03 / * 03$ & $19(38.0)$ & $2(3.8)^{\mathrm{a}}$ \\
$* 03 / * 04$ & $6(12.0)$ & $0(0)^{\mathrm{b}}$ \\
$* 03 / * 10$ & $4(8.0)$ & $0(0)$ \\
$* 03 / * 13$ & $5(10.0)$ & $1(1.9)$ \\
$* 03 / * 14$ & $3(6.0)$ & $2(3.8)$ \\
$* 03 / * 15$ & $1(2.0)$ & $3(5.7)$ \\
$* 04 / * 11$ & $1(2.0)$ & $2(3.8)$ \\
$* 04 / * 15$ & $0(0)$ & $5(9.4)^{\mathrm{c}}$ \\
$* 07 / * 15$ & $0(0)$ & $9(17.0)^{\mathrm{d}}$ \\
$* 11 / * 15$ & $1(2.0)$ & $5(9.4)$ \\
\hline
\end{tabular}

Number (\%) of diabetic and control subjects with each genotype. Only genotypes occurring in more than two subjects are shown (total number of genotypes $=36$ ) NB. All subjects with DRB1*03/*04 genotype carried the DR4.DQ8 haplotype ${ }^{\mathrm{a}} p<1 \times 10^{-4}, \quad p_{\mathrm{c}}<3.6 \times 10^{-3}, \quad \mathrm{RR}=12.75 \quad[3.51-46.37]$; ${ }^{\mathrm{b}} p=0.011, \quad p_{\mathrm{c}}=\mathrm{NS} ; \quad{ }^{\mathrm{c}} p=0.033, \quad p_{\mathrm{c}}=\mathrm{NS} ; \quad{ }^{\mathrm{d}} p=1.77 \times 10^{-3}$, $p_{\mathrm{c}}=\mathrm{NS}$

quency among the diabetic patients compared with the control subjects $\left(p_{\mathrm{c}}=\mathrm{NS}\right)$ (Table 1$)$.

The DRB1*04.DQA1*03.DQB1*0302 (DR4. $D Q 8)$ haplotype was not associated with susceptibility to Type I diabetes in our study group (Table 1 ). Among the DR4.DQ8-positive subjects, 7 out of 10 $(70 \%)$ diabetic patients carried DRB1*04 alleles associated with a high risk of diabetes (DRB1*0401, *0402 and *0405) compared with 2 out of 7 (28.6\%) control subjects ( $p=$ NS) (Table 2). In contrast, the low-risk DRB $1 * 0403$ allele was present in 2 out of 10 $(20 \%)$ diabetic subjects compared with 4 out of 7 $(57.1 \%)$ control subjects ( $p=$ NS).

The homozygous genotype, DRB $1 * 03 / * 03$, was significantly more frequent among the diabetic patients than among the control group (Table 3 ). The DRB $1 * 03 / * 04$ genotype was also increased in frequency among the diabetic subjects, whereas DRB $1 * 04 / * 15$ and DRB1*07/*15 were less frequent among the diabetic patients than among the control group ( $p_{\mathrm{c}}=\mathrm{NS}$ in all three cases).

The transmission disequilibrium test (TDT) was used to analyse the $H L A$ haplotype data from 39 complete simplex families. These families consisted of two unaffected parents, the diabetic proband and between one and six unaffected siblings (mean 2). The DR3.DQ2 and DR4.DQ8 haplotypes were transmitted from the unaffected parents to the diabetic offspring more frequently than to the unaffected offspring $\left(p<1 \times 10^{-4}\right.$ and $p<0.025$ respectively) (Table 4). In contrast, the DRB1*1502.DQA $1 * 0103$. DQB1*0601 haplotype was transmitted preferentially to the unaffected siblings (Table 4). No other haplotypes had transmission distortion (data not shown).

Islet-related autoantibodies were measured in 48 of the diabetic children and 51 of the healthy control 
Table 4. Transmission of the $D R / D Q$ haplotypes to diabetic and non-diabetic offspring in simplex families

\begin{tabular}{|c|c|c|c|}
\hline Haplotype & Offspring & $\begin{array}{l}\text { Transmitted } \\
\text { haplotypes }\end{array}$ & $\begin{array}{l}\text { Non-trans- } \\
\text { mitted } \\
\text { haplotypes }\end{array}$ \\
\hline \multicolumn{4}{|c|}{$\begin{array}{l}\text { DRB } 1 * 03 . \text { DQA } 1 \\
* 05 \text { DOB } 1 * 02\end{array}$} \\
\hline & Diabetic & 45 & 5 \\
\hline & Unaffected & 34 & 29 \\
\hline \multicolumn{4}{|c|}{ DRB1*04.DQA1 } \\
\hline & Diabetic & 8 & 4 \\
\hline & Unaffected & 7 & 18 \\
\hline \multicolumn{4}{|c|}{$\begin{array}{l}\text { DRB1*1502.DQA1 } \\
* 0103 . \mathrm{DQB} 1 * 0601\end{array}$} \\
\hline & Diabetic & 0 & 8 \\
\hline & Unaffected & 4 & 5 \\
\hline
\end{tabular}

Comparison of haplotype distribution to affected and unaffected offspring; DRB1*03.DQA $1 * 05 . \mathrm{DQB} 1 * 02, \quad \mathrm{X}^{2}=17.21$, $p<1 \times 10^{-4} ; \quad$ DRB1*04.DQA1*03.DQB1*0302, $\quad \mathrm{X}^{2}=5.03$, $p<0.025 ;$ DRB1*1502.DQA1*0103.DQB1*0601, $\mathrm{X}^{2}=4.65$, $p<0.05$

children (Table 5); one or more of these markers was found in $43(89.6 \%)$ of the diabetic patients compared with $6(11.8 \%)$ of the control subjects $\left(p<1 \times 10^{-6}\right)$. Of the diabetic patients, $14(29.2 \%)$ were positive for a single antibody, $13(27.1 \%)$ possessed two, $11(22.9 \%)$ had three antibodies and all four antibodies were detected in $5(10.4 \%)$ children. In the control group, four children $(7.8 \%)$ were positive for a single autoantibody and two subjects $(3.9 \%)$ possessed two autoantibodies.

Positivity for ICA was shown to decline with increasing disease duration, from $55.6 \%$ among patients who developed diabetes less than 1 year before antibody measurement (short duration, $n=18$ ) to $18.2 \%$ among those with disease duration longer than 6 years $(n=11) \quad(p<0.01$ using the Kolmogorov-Smirnov test). A similar, but smaller, decline was observed for GAD antibodies (from $55.6 \%$ to $36.4 \%)(p<0.01)$. Antibodies to IA-2ic were found with similar frequencies among patients recruited within 1 year of disease onset $(16.7 \%)$ and those with longer disease duration $(18.2 \%)$. Among the subjects with short disease duration, there was no association between age of onset and the presence of antibodies to insulin $(p>0.1)$.

The DR4.DQ8 haplotype was significantly more frequent among the children positive for IA-2ic antibodies than among those negative for this humoral marker $(57.1 \%$ vs $10.5 \%$ respectively, $p=0.026)$. There was also a trend towards an association between this haplotype and ICA; $26.7 \%$ ICA-positive subjects carried the DR4.DQ8 haplotype compared with $13.3 \%$ ICA-negative patients $(p=\mathrm{NS})$. The $D R 3 . D Q 2$ haplotype was increased in frequency among patients positive for GAD autoantibodies
Table 5. Frequency of islet-related antibodies among diabetic and control subjects

\begin{tabular}{lcl}
\hline Antibody & $\begin{array}{l}\text { Type I diabetic } \\
\text { patients (\%) } \\
n=48\end{array}$ & $\begin{array}{l}\text { Control } \\
\text { subjects (\%) } \\
n=51\end{array}$ \\
\hline ICA & $17(35.4)$ & $2(3.9)^{\mathrm{a}}$ \\
GAD & $27(56.3)$ & $2(3.9)^{\mathrm{b}}$ \\
IA-2ic & $8(16.7)$ & $2(3.9)^{\mathrm{c}}$ \\
Insulin & $41(85.4)$ & $2(3.9)^{\mathrm{d}}$ \\
ICA + GAD & $1(2.1)$ & $1(2.0)$ \\
ICA + IA-2ic & $0(0)$ & $0(0)$ \\
ICA + insulin & $1(2.1)$ & $0(0)$ \\
GAD + IA-2ic & $0(0)$ & $1(2.0)$ \\
GAD + insulin & $11(22.9)$ & $0(0)^{\mathrm{e}}$ \\
IA-2ic + insulin & $0(0)$ & $0(0)$ \\
ICA + GAD + IA-2ic & $1(2.1)$ & $0(0)$ \\
ICA + GAD + insulin & $8(16.7)$ & $0(0)^{\mathrm{f}}$ \\
ICA + IA-2ic + insulin & $1(2.1)$ & $0(0)$ \\
GAD + IA-2ic + insulin & $1(2.1)$ & $0(0)$ \\
ICA + GAD + IA-2ic + insulin & $5(10.4)$ & $0(0)^{\mathrm{g}}$ \\
\hline Number (\% ) of diabetic and &
\end{tabular}

Number (\%) of diabetic and control subjects with each antibody: ${ }^{\mathrm{a}} p<1 \times 10^{-4} ; \quad{ }^{\mathrm{b}} p<1 \times 10^{-6} ; \quad{ }^{\mathrm{c}} p<0.05 ; \quad{ }^{\mathrm{d}} p<1 \times 10^{-6}$; ${ }^{\mathrm{e}} p=1.8 \times 10^{-4} ;{ }^{\mathrm{f}} p=2.2 \times 10^{-3} ;{ }^{\mathrm{g}} p=0.02$

(84.0\% vs $65.0 \%$ among GAD-negative subjects) and among subjects with insulin antibodies (78.9\% vs $57.1 \%$ among subjects lacking insulin antibodies) ( $p=$ NS in both cases).

\section{Discussion}

A high-resolution genomic typing technique was used to investigate the role of $H L A-D R$ and $H L A$ $D Q$ alleles as susceptibility determinants for Type I diabetes in an Indo-Aryan population. The DRB1*03. DQA1*05.DQB1*02 (DR3.DQ2) haplotype was associated with a statistically significantly increased risk of the disease in our cohort. Homozygosity for DRB1*03 was also positively associated with diabetes. These observations are consistent with the findings of earlier studies of Indo-Aryan populations which showed a strong disease association with the DR3 antigen [9-11]. The relative risk value for DRB1*03 in our study $(\mathrm{RR}=11.40)$ is of similar magnitude to that reported for DR3 in an indigenous cohort in India $(\mathrm{RR}=10.52)$ [11]. Furthermore, the frequency of the DRB $1 * 03$ allele in our control group $(22.6 \%)$ is similar to that observed for DR3 in the indigenous healthy Indian cohort $(25.7 \%)$, suggesting that the subjects in our study are genetically representative of the Indo-Aryan population of north India. The RR values for $\mathrm{DRB} 1 * 03(\mathrm{RR}=11.40)$ and the DRB1*03/*03 genotype $(R R=12.75)$ in our Indian cohort are higher than those observed in an Anglo-European study group resident in Birmingham $(\mathrm{RR}=4.14$ and $\mathrm{RR}=5.71$, respectively; unpublished observation). 
Heterogeneity tests, however, suggest that these differences are not statistically significant (DRB1*03 alone; $\mathrm{X}^{2}=3.37, p=\mathrm{NS}$ : DRB $1 * 03 / * 03 ; \mathrm{X}^{2}=0.81$, $p=\mathrm{NS}$ ). This could be because the number of subjects in the Indo-Aryan cohort was too small to show statistical significance for a moderate increase in relative risk (two to threefold). Alternatively, it could indicate that the risk conferred by DRB $1 * 03$ is similar in both ethnic groups.

The association between Type I diabetes and the $D R 3 . D Q 2$ haplotype in our Indo-Aryan cohort was further confirmed by the analysis of simplex families, which showed that this haplotype was transmitted significantly more frequently to the diabetic offspring of unaffected parents than to the non-diabetic siblings.

The DRB1*04.DQA1*03.DQB1*0302 (DR4. $D Q 8)$ haplotype did not differ significantly in frequency between the diabetic and control subjects in our study. This finding is consistent with a study of Indo-Aryans from the New Delhi area of India which reported no disease association with DR4 [11]. In contrast, a study of a cohort of Indo-Aryans resident in the United Kingdom showed a weak positive disease association with this antigen [9]. The discrepant observations between different studies could largely be attributable to the small number of subjects investigated. Although DR4.DQ8 was not significantly associated with disease in our case control study, we cannot exclude the possibility that this marker has a minor influence on disease risk. It is important to note that the majority of diabetic subjects positive for this haplotype carried $D R B 1$ alleles associated with a high risk of Type I diabetes in Europid populations (DRB1*0401,*0402 and *0405), whereas the control subjects predominantly carried alleles associated with a lower risk of disease (DRB1*0403, *0404 and $* 0407$ ) [21]. Furthermore, heterozygosity for DRB $1 * 03 / * 04$ was increased in frequency among the diabetic patients compared with the control subjects and the DRB $1 * 03 / * 04$ genotype was associated with a higher relative risk compared with DRB1*03 alone (15.63 vs 11.40 , respectively; $p=\mathrm{NS}$ ). The strongest evidence to support a role for $D R 4 . D Q 8$ in disease susceptibility was, however, provided by the family study which showed that this haplotype was transmitted preferentially to the diabetic offspring. In summary, the $D R 4 . D Q 8$ haplotype appears to be a minor susceptibility marker for Type I diabetes in our Indo-Aryan cohort and a larger study may help to define its role in this ethnic group.

Protection from Type I diabetes has been associated with $D R 2$ in both Europid and Indo-Aryan populations $[2,9,11]$. In the former ethnic group, this protective influence is largely attributed to the DRB1*1501.DQA1*0102.DQB1*0602 (DR15.DQ6) haplotype. This haplotype, however, was not a major protective marker in our Indo-Aryan cohort, as it was rare in both diabetic and control groups. In our case control study, five haplotypes were associated with a decreased risk of disease. The TDT showed that the DRB1*1502.DQA1*0103.DQB1*0601 haplotype was negatively associated with diabetes in the simplex families.

Islet cell antibodies (ICA) were detected in 35\% of our Indo-Aryan diabetic children. This is similar to the ICA frequencies reported previously in IndoAryans with established diabetes [6,10-13]. The apparently low prevalence of ICA in the present study is largely due to the time lag between disease onset and serum sampling for antibody measurement. As in Europids with Type I diabetes, the highest prevalence of ICA in our Indo-Aryan cohort was observed in diabetic patients sampled within 1 month of disease onset (67\% vs approximately $80-90 \%$ in Europids) $[3,22]$. Beyond this period, antibody positivity declined with increasing disease duration, as reported previously in both Europid and Indo-Aryan populations [12]. The presence of ICA at disease onset is associated with $H L A-D R 4$ and $H L A-D Q 8$ in Europid populations $[22,23]$. In our Indo-Aryan cohort there was a trend towards an association between ICA positivity and the DR4.DQ8 haplotype, although this was not statistically significant. This could be due to the time of serum sampling in our study, as many of the subjects might have lost ICA positivity before antibody analysis. Thus the association with $D R 4 . D Q 8$ could possibly be observed at diagnosis but decrease in statistical significance with time as the ICA concentrations decline.

Autoimmunity to GAD in the Indo-Aryan cohort had similar characteristics to those reported previously in Europid diabetic patients. Antibodies to GAD were present at similar frequencies in both ethnic groups $(56 \%$ in the Indo-Aryan cohort compared with $50-80 \%$ in newly diagnosed Europids [3, 4, 22]) and showed a similar time course for persistence in the circulation. Autoimmunity to GAD is associated with $H L A-D R 3$ and $H L A-D Q 2$ in Europid populations [23-25]. In our Indo-Aryan cohort we observed a trend towards a positive association between GAD antibody status and the $D R 3 . D Q 2$ haplotype, but this was not statistically significant. This could reflect the young age of disease onset in our patients as the association between GAD antibodies and $H L A$ genes has been reported to be weak among patients diagnosed below the age of 15 years [25].

Autoantibodies to IA-2ic were a poor marker for Type I diabetes in the Indo-Aryan cohort, occurring in only $17 \%$ of our diabetic patients (compared with $50-80 \%$ of Europid diabetic patients at disease onset $[4,22,24])$. This low frequency could not be attributed to the time lag between disease onset and antibody measurement, as the per cent of positivity for IA-2ic antibodies was found to be similarly low among patients sampled within 1 year of diagnosis and those 
with disease duration in excess of 6 years. The IA-2ic antibodies were shown to occur most frequently among diabetic patients positive for the DR4.DQ8 haplotype. This is consistent with the findings in Europid populations [22,24], which have suggested that the DRB1*0401 allele could have a more important role in IA-2ic antibody formation than $D Q 8$ [22]. We were, however, unable to confirm this in our Indo-Aryan diabetic cohort due to the small number of IA-2ic-positive subjects in this group. The close relation between antibody status and HLA type suggests that the low frequency of IA-2ic antibodies among Indo-Aryan diabetic patients reflects the absence of a disease association with DRB $1 * 04$ in this population.

The frequency of antibodies to insulin in our IndoAryan diabetic cohort increased statistically significantly with increasing disease duration, suggesting that they were predominantly a consequence of insulin therapy rather than an autoimmune response to endogenous insulin. Further support for this possibility was provided by two observations: residual endogenous insulin production was found in only 9 of the 41 insulin antibody-positive patients (data not shown) and 5 of the 7 diabetic children who lacked insulin antibodies had received insulin therapy for less than 8 months. It is not clear why such a high proportion of diabetic patients develop antibodies to human insulin.

Islet-related antibodies were detected in $11.8 \%$ of the Indo-Aryan control children. Although this percentage seems rather high, it is important to note that the majority of these subjects (four out of six) were positive for a single autoantibody and only two children possessed two antibodies. These data are similar to the frequency of islet antibodies reported in healthy schoolchildren of Anglo-European origin $(9.4 \%)$ [26].

Our study shows that Type I diabetes in a cohort of Indo-Aryans resident in the United Kingdom is similar to the disease seen in Anglo-Europeans, but exhibits important genetic and immunological differences. The HLA-DR3.DQ2 haplotype is the major disease susceptibility marker in the Indo-Aryan group, with $D R 4$. $D Q 8$ apparently contributing less to disease risk. This contrasts with the Anglo-European population in which $\mathrm{DRB} 1 * 04$ confers the greatest risk of disease and DRB $1 * 03$ has a less important role [2]. The two ethnic groups also differ in the $H L A$ markers which confer protection against diabetes. The most important immunological difference between the two groups is the low frequency of autoantibodies to IA-2ic in the Indo-Aryan diabetic patients. This might have important implications for disease prediction in this population. It has been suggested that Europids at high risk of Type I diabetes can be identified by screening for a combination of autoantibodies to GAD and IA-2ic [26]. In the Indo-
Aryan population however, this approach is, unlikely to be of greater predictive value than screening for GAD antibodies or ICA or both.

Acknowledgements. This work was supported by the British Diabetic Association (grant reference number RD/0000941) and by the Autoimmune Diseases Charitable Trust (London).

We thank paediatricians at the regional diabetes clinics in Birmingham for referring patients for the study.

We are extremely grateful to M. Shattock, P. Collins and R. Foxon (St. Bartholomew's and the Royal London School of Medicine and Dentistry, London) for doing the antibody assays for ICA, GAD and IA-2ic, and E. Bonifacio (San Raffaele Scientific Institute, Milan) for determination of the insulin antibodies. We also thank M. Coulson for technical assistance with the HLA typing.

\section{References}

1. Bottazzo GF (1993) Banting Lecture. On the honey disease. A dialogue with Socrates. Diabetes 42: 778-800

2. Cavan DA, Jacobs KH, Penny MA et al. (1993) Both DQA1 and DQB1 genes are implicated in HLA-associated protection from Type I (insulin-dependent) diabetes mellitus in a British Caucasian population. Diabetologia 36: 252-257

3. Bonifacio E, Genovese S, Braghi S et al. (1995) Islet autoantibody markers in IDDM: risk assessment strategies yielding high sensitivity. Diabetologia 38: 816-822

4. Leslie RDG, Atkinson MA, Notkins AL (1999) Autoantigens IA-2 and GAD in Type I (insulin-dependent) diabetes. Diabetologia 42: 3-14

5. Ahuja MMS, Sivaji L, Garg VK, Mitroo P (1972) Prevalence of diabetes in northern India (Delhi area). Horm Metab Res 4: 321-324

6. Bhatia E, Mehra NK, Malaviya AN, Ahuja MMS (1986) HLA and autoimmunity in North Indian type I (insulin-dependent) diabetic multiplex families. Horm Metab Res 18: 331-334

7. Mather HM, Keen H (1985) The Southall diabetes survey: prevalence of known diabetes in Asians and Europeans. BMJ 291: 1081-1084

8. Odugbesan O, Barnett AH (1985) Asian patients attending a diabetes clinic. BMJ 290: 1051-1052

9. Odugbesan O, Fletcher J, Mijovic C, Mackay E, Bradwell AR, Barnett AH (1987) The HLA-D associations of Type I (insulin-dependent) diabetes in Punjabi Asians in the United Kingdom. Diabetologia 30: 618-621

10. Bodansky HJ, Beverley DW, Gelsthorpe K, Saunders A, Bottazzo GF, Haigh D (1987) Insulin dependent diabetes in Asians. Arch Dis Child 62: 227-230

11. Bhatia E, Mehra NK, Taneja V, Vaidya MC, Ahuja MMS (1985) HLA-DR antigen frequencies in a North Indian type I diabetic population. Diabetes 34: 565-567

12. Odugbesan O, Fletcher JA, Sanders A, Bradwell AR, Bottazzo GF, Barnett AH (1988) Autoantibodies in IndianAsians with insulin-dependent diabetes in the UK. Postgrad Med J 64: 357-360

13. Srikanta S, Malaviya AN, Mehra NK, Vaidya MC, Geevarghese PJ, Ahuja MM (1981) Autoimmunity in type I (insulin-dependent) diabetes mellitus in North India. J Clin Immunol 1: 169-173

14. Bunce M, O’Neill CM, Barnardo MC et al. (1995) Phototyping: comprehensive DNA typing for HLA-A, -B, -C, -DRB1, -DRB3, -DRB4, -DRB5 and -DQB1 by PCR with 
144 primer mixes utilizing sequence-specific primers (PCRSSP). Tissue Antigens 46: 355-367

15. Bonifacio E, Bingley P, Shattock M et al. (1990) Quantification of islet cell antibodies and prediction of insulin-dependent diabetes. Lancet 335: 147-149

16. Petersen JS, Hejnaes KR, Moody A et al. (1994) Detection of $\mathrm{GAD}_{65}$ antibodies in diabetes and other autoimmune diseases using a simple radioligand assay. Diabetes 43: 459-467

17. Naserke HE, Dozio N, Ziegler A-G, Bonifacio E (1998) Comparison of a novel microassay for insulin autoantibodies with the conventional radiobinding assay. Diabetologia 41: 681-683

18. Verge CF, Stenger D, Bonifacio E et al. (1998) Combined use of autoantibodies (IA-2 autoantibody, GAD autoantibody, insulin autoantibody, cytoplasmic islet cell antibodies) in type I diabetes: Combinatorial Islet Autoantibody Workshop. Diabetes 47: 1857-1866

19. Mathews JD (1984) Statistical aspects of immunogenetic association with disease. In: Simons MJ, Tait BD (eds) Detection of immune-associated genetic markers of human disease. Churchill-Livingstone, London, pp 106-136

20. Spielman RS, McGinnis RE, Ewens WJ (1993) Transmission test for linkage disequilibrium: the insulin gene region and insulin-dependent diabetes mellitus (IDDM). Am J Hum Genet 52: 506-516
21. She J-X (1996) Susceptibility to type I diabetes: HLA-DQ and DR revisited. Immunol Today 17: 323-329

22. Sanjeevi CB, Hagopian WA, Landin-Olsson et al. (1998) Association between autoantibody markers and subtypes of DR4 and DR4-DQ in Swedish children with insulin-dependent diabetes reveals closer association of tyrosine pyrophosphatase autoimmunity with DR4 than DQ8. Tissue Antigens 51: 281-286

23. Hagopian W, Sanjeevi CB, Kockum I et al. (1995) Glutamate decarboxylase-, insulin- and islet cell antibodies and HLA typing to detect diabetes in a general populationbased study of Swedish children. J Clin Invest 95: 1505-1511

24. Genovese S, Bonfanti R, Bazzagaluppi E et al. (1996) Association of IA-2 autoantibodies with HLA DR4 phenotypes in IDDM. Diabetologia 39: 1223-1226

25. Serjeantson SW, Court J, Mackay IR et al. (1993) HLADQ genotypes are associated with autoimmunity to glutamic acid decarboxylase in insulin-dependent diabetes mellitus patients. Hum Immunol 38: 97-104

26. Bingley PJ, Bonifacio E, Williams AJK, Genovese S, Bottazzo GF, Gale EAM (1997) Prediction of IDDM in the general population. Strategies based on combinations of autoantibody markers. Diabetes 46: 1701-1710 